\title{
Objective Evaluation of Hand for Futon Cloth
}

\author{
Mitsuo Matsudaira* and Masahiko Kubo** \\ * Faculty of Education, Kanazawa University, Kanazawa \\ ** Mikawa Laboratory, Daiwabo Co., Ltd., Mikawa \\ Based on the Journal of the Textile Machinery Society of Japan, Transactions, \\ Vol.44,No.11,T201-T210(1991), Vol.46,No.1,T18- T26(1993), Vol46,No.9,T207-T214(1993).
}

\begin{abstract}
In order to evaluate fabric hand of Futon cloth objectively, five primary hands for Futon cloth were selected and defined from the opinions of experts who engaged in allied industry and distribution of Futon cloth. They are "SOFUTOSA", "KOSHI-F", "NUMERI-F", "FUKURAMI" and "GASATSUKI", and can explain 83\% of the descriptions used for hand evaluation. Objective evaluation equation (DM-02) of Futon cloth was developed from its basic mechanical characteristics by the stepwise block residual regression method with high accuracy and with small errors. The equation for evaluating Total Hand Value (THV) of Futon cloth objectively (DM11) was also derived from seven parameters, namely, five primary hands, air resistance and water regain by the stepwise block residual regression method. The equation obtained showed high accuracy, small errors and usefulness in practical application. Subjective evaluation of the primary hands and THV by consumers showed a little larger variation between each panel than that by experts. However, mean value of each primary hand and THV by consumers agreed well with that by experts. Therefore, the objective evaluation equation derived from subjective evaluation of experts can be used widely for objective evaluation of primary hands and THV (DM-02, DM-11). Experts take care of the degree of "SOFUTOSA" for the evaluation of THV first of all, but, consumers judge the degree of "GASATSUKI" for it.
\end{abstract}

\section{Introduction}

Objective evaluation method of fabric hand from the basic mechanical characteristics of fabric was developed by Kawabata and Niwa evaluation equations are used widely for various end- uses such as men's or women's suits, women's fine dresses, outer or inner wear knits, etc $3: 4]$. However, those equations are applied mainly for apparel uses. If those equations are used for Futon cloth or curtain cloth, results of the objective evaluation equations are not necessarily satisfied, as the standards of fabric hand are different from apparel uses.

Further, fabric hand of Futon cloth had not been studied yet. In this paper, first, five primary hands are defined from the opinions of experts who long engaged in Futon industry. Secondly, objective evaluation equations of primary hands of Futon cloth are developed using basic mechanical characteristics of Futon cloth obtained by KES system ${ }^{5}$. Thirdly, objective evaluation equation of Total Hand Value (THV), which is an overall quality of fabric, is developed from the primary hand values evaluated objectively. Lastly, the difference of subjective evaluation between experts and consumers is discussed.

\section{Method}

\subsection{Definition of primary hands of futon cloth}

Hand Evaluation and Standardization Committee (HESC) 113 organized by Kawabata in the Textile Machinery Society of Japan defined primary hands for men's suits fabrics (winter and summer) and women's fine dress fabrics. These primary hands are widely used for evaluation of other fabrics such as outer or inner wear knits and various end-use fabrics.

However, when we asked some experts who long engaged in Futon cloth industry, two points were recognized. 1: It is not satisfactory to use only terms and definitions by HESC. 2: Different meanings are included in the definition by HESC. Therefore, we tried to select and define primary hands of Futon cloth by asking 20 experts who engaged in Futon cloth industry (finishing, engineering, sales, distribution) for more than 5 years. Questions were: 1: What are basic and important terms to evaluate fabric hand of Futon cloth? 2: What are meanings and contents of them? Then, 10 experts from the above-mentioned 20 experts ( 2 or 3 from each field) gathered together with the authors and terms appeared most frequently in the answers were selected and standardized. The 
minimum and necessary number of terms were defined as primary hands of Futon cloth.

\subsection{Futon cloth samples}

Futon cloth samples are shown in Table 1, which were selected from Futon cloths widely produced and sold in Japan now $(1988$ - 1991). Their hands ranged widely from very hard to quite soft.

Table 1 Futon Cloth Samples

\begin{tabular}{|c|c|c|c|}
\hline \multicolumn{2}{|c|}{ Material Number of Samples } & \multirow{2}{*}{$\begin{array}{l}\text { Structure } \\
\text { Plain }\end{array}$} & \multirow{2}{*}{$\begin{array}{r}\begin{array}{c}\text { Number } \\
\text { of } \\
\text { Sample }\end{array} \\
54\end{array}$} \\
\hline Cotton $100 \%$ & 79 & & \\
\hline Cotton/Silk & 10 & Satin & 42 \\
\hline Cotton/Polyester & 9 & Twill & 6 \\
\hline Silk $100 \%$ & 4 & Dobby & 5 \\
\hline Cotton/Wool & 3 & & \\
\hline Cotton/Rayon & 2 & & \\
\hline Total & 107 & Total & 107 \\
\hline
\end{tabular}

\subsection{Subjective evaluation of primary hands and total hand of futon cloth}

Futon cloth samples were graded subjectively in point of primary hands mentioned above by the similar manner as HESC 111 . The procedure of grading is shown in Fig.1. Samples were ranked in two steps. At first, samples were divided into 3 groups depending on the level of primary hands. Then, each group was divided into 3 groups. In the case of fabrics having extreme high or low level were separated from the groups. So, eleven groups were made, and points from 0 to 10 were assigned to each group. Thus, primary hand value of a fabric was determined subjectively by 10 experts mentioned above plus 2 retailers who engaged in retailing over 30 years.

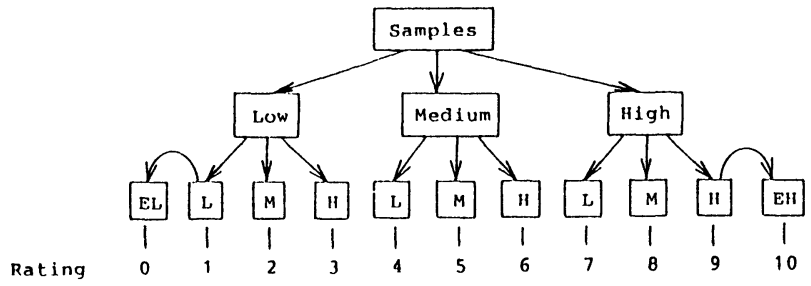

Fig. 1 Procedure for subjective evaluation of Futon cloth samples.

Total Hand Value (THV) of a Futon cloth fabric was evaluated subjectively by the similar manner to HESC (1) The procedure of grading is shown in Fig.2.

Samples were divided into 4 groups depending on fabric overall quality as Futon cloth, namely, good, average, poor and out of use. Then, excellent fabrics were separated from the good group, and poor fabrics from the poor. So, six groups of fabrics were made, and points from 0 to 5 were assigned to each group according to THV. There are opinions within the experts that thermal insulation value and comfortability of Futon cloth should be considered for the evaluation of THV. Therefore, those properties were also judged by imaginating such state as lying in the Futon made from the same Futon cloth.

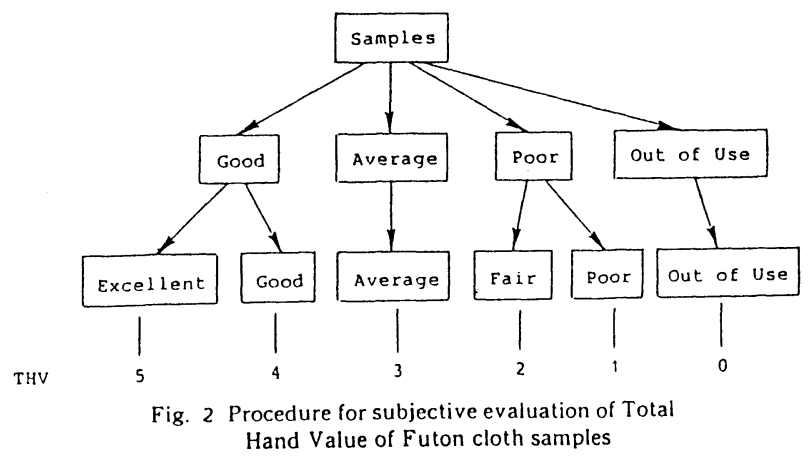

\subsection{Objective evaluation of primary hands and total hand of futon cloth}

\subsubsection{Objective evaluation of primary hand value}

Basic mechanical characteristics were obtained for 107 samples mentioned in $2-2$ by KES system ${ }^{15}$. The regression lines were calculated between those values and subjective values obtained in 2-3. But, the compressional property was measured by high-sensitivity conditions [ 6 ] [ 7 ] of KES system.

The reason is as follows. At first, thickness of Futon cloth is as thin as women's fine dress fabrics, and feeling of FUKURAMI of Futon cloth could be judged with small pressure. So, high-sensitivity condition ( $1 / 5$ of standard condition) is better for compressional property of Futon cloth. Although the testing condition for tensile property of women's fine dress fabrics is high-sensitivity condition, standard condition was used for tensile property of Futon cloth. It was because that Futon cloth was treated by polyurethane resin and showed very little tensile strain at high-sensitivity condition ( $1 / 10$ of standard condition).

In order to clarify the contribution of the basic mechanical property on primary hands and to avoid multi-collinearity ${ }^{[8]}$, a method of stepwise block residual regression developed by Kawabata ${ }^{[1]}$ was used for regression. Characteristics (parameters) and mechanical properties measured by KES system are shown in Table 2. The method of stepwise block residual regression is as follows:

1) Multiple regression equations $Y$ between subjective values $\mathrm{y}$ and mechanical parameters of each block were obtained. Then, regressed values $\tilde{Y}$ was calculated for all samples. 


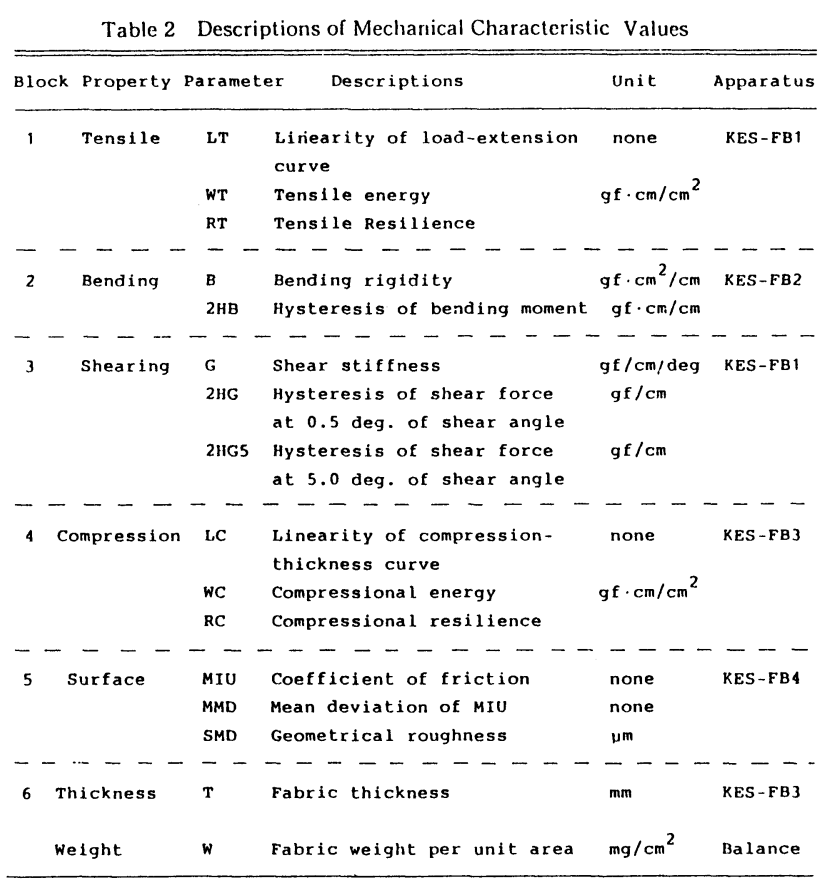

$$
\begin{aligned}
\tilde{Y}_{1}= & C_{0}+C_{1} X_{1}+C_{2} X_{2}+C_{3} X_{3} \\
\widetilde{Y}_{2}= & C_{0}+C_{4} X_{4}+C_{5} X_{5} \\
& \ldots \\
\widetilde{Y}_{6}= & C_{0}+C_{15} X_{15}+C_{16} X_{16}
\end{aligned}
$$

2) The block showing the highest correlation between $y$ and $\tilde{Y}_{i}$ was decided to be the 1st block. The regression equation was denoted as $Y$ (1) .

3) The residue between y and regressed value of the 1st block; $y-\tilde{Y}$ (1) , was calculated for all samples. Multiple regression equations $Y$ between the residue and the mechanical parameters of remaining blocks were obtained. Then, regressed values $\tilde{Y}$ were calculated for all samples.

4) The 2nd block was decided to be $Y$ (2) which had the highest correlation between y and $\tilde{Y}_{1,}+\tilde{Y}_{i}$.

Then the total regression equation became $Y(1)+Y$ (2)

5) 6 blocks were decided by the similar manner, getting the following equation finally.

$$
Y=C_{0}+\sum_{i=1}^{16} C_{i} X_{i}
$$

For the mechanical parameters, it is convenient to use values normalized by mean and standard deviation.

$$
Y=C_{0}+\sum_{i=1}^{16} C_{i} \frac{X_{i}-\overline{X_{i}}}{\sigma_{i}}
$$

where , $Y$ : primary hand value evaluated objectively
$C_{0}, C_{\text {i }}$ : constants ( $\mathrm{i}=1$ to 16 )

$X_{\mathrm{i}}:$ i-th mechanical parameter

$\bar{X}_{\mathrm{i}}$ : mean value of the population of $X$ i

$\sigma$ i : standard deviation of the population of $X_{\text {i }}$

2.4.2 Objective evaluation of total hand value (THV)

In addition to 5 primary hands calculated objectively by equ.(5), air resistance of fabric was chosen on behalf of thermal insulation value of Futon cloth. Air resistance was calculated by the following equation:

$$
R=12.45 / x
$$

where , $R$ : air resistance $(\mathrm{kPa} \cdot \mathrm{s} / \mathrm{m})$

$x$ : amount of air measured by the Fragile method $\left(\mathrm{cm}^{3} / \mathrm{cm}^{2} / \mathrm{s}\right)$

If an air permeability tester developed by Kawabata

[ 9 ] (KES-F8-AP1, Kato Tech Co.) is used to measure air resistance of Futon cloth, the air resistance is obtained directly.

Further, water regain (unit; \%) at a standard condition $\left(20{ }^{\circ} \mathrm{C}, 65 \% \mathrm{RH}\right)$ was chosen on behalf of comfortability of Futon cloth. For example, water regain of Futon cloth made of polyester/cotton (20\%/80\%) blended yarns was calculated on the weighted average of water regain of each fiber. These 7 parameters affect on THV, so squared values of these parameters were also used as variables to find out the optimum value of each parameter after the manner similar to HESC $\left[\begin{array}{ll}1\end{array}\right]$. Therefore, the regression between 14 objective values, that is, 7 blocks of 5 primary hands, air resistance and water regain and one subjective value of THV was calculated by the stepwise block residual regression method.

Final objective evaluation equation of THV of Futon cloth was obtained as follows:

$$
T H V=C_{00}+\sum_{i=1}^{7} C_{1 i} \frac{Y_{i}-\overline{Y_{i}}}{\sigma_{1 i}}+\sum_{i=1}^{7} C_{2 i} \frac{Y_{i}^{2}-\overline{Y_{i}^{2}}}{\sigma_{2 i}}
$$

where, $C_{0} 0, C_{1}$ i,$C_{2}$ i $\quad:$ constants (i=1 to 7)

$Y_{\mathrm{i}}: \mathrm{i}$ - th primary hand value

$\bar{Y}_{i}:$ mean value of the population of $\mathrm{Y}_{\mathrm{i}}$

$\overline{Y_{i}{ }^{2}}:$ mean value of square of the population of $Y$ i

$\sigma_{1}, \mathrm{i}:$ standard deviation of the population of $Y_{\mathrm{i}}$

$\sigma \quad 2$ i : standard deviation of the population of $Y i^{2}$

\section{Results}

3.1 Definitions of primary hands of futon cloth 
Table 3 Terms and Definitions of Primary Hands of Futon Cloth

\begin{tabular}{|c|c|c|c|c|c|}
\hline No. & Term & Definition & Remark & eque & ncy \\
\hline 1 & SOFUTOSA & $\begin{array}{l}\text { Soft feeling with flexible, } \\
\text { smooth and bulky touch. }\end{array}$ & Same defintion as HESC. & 26 & \% \\
\hline 2 & KOSHI-F & $\begin{array}{l}\text { Stiff feeling with springy } \\
\text { property. }\end{array}$ & $\begin{array}{l}\text { A feeling of the fabric } \\
\text { having compact weaving } \\
\text { density. Anti-drape } \\
\text { stiffness is also in- } \\
\text { cluded in this term. }\end{array}$ & 19 & 8 \\
\hline 3. & NUMERI-F & $\begin{array}{l}\text { Smooth and moist feeling, } \\
\text { a little sticky to hand. }\end{array}$ & $\begin{array}{l}\text { A surface feeling come } \\
\text { from calendar treatment } \\
\text { with resin(polyurethane). }\end{array}$ & 13 & 8 \\
\hline 4. & FUKURAMI & $\begin{array}{l}\text { A feling come from bulky, } \\
\text { rich and well formed feeling. } \\
\text { Springy in compression with } \\
\text { warm feeling. }\end{array}$ & Same definition as HESC. & 13 & 8 \\
\hline 5. & GASATSUKI & A dry rustling feeling. & $\begin{array}{l}\text { A feeling of the fabric } \\
\text { having hard and rough } \\
\text { touch with rustling sound. }\end{array}$ & 12 & \& \\
\hline
\end{tabular}

Terms and definitions of primary hands for Futon cloth defined by experts are shown in Table 3, together with the frequency of those terms. $83 \%$ of all the terms described as they like concerning fabric hand of Futon cloth are occupied by these 5 primary hands. "SOFUTOSA" and "FUKURAMI" define the same as HESC for clothes. "KOSHI-F" and "NUMERI-F" mean a little different from the definitions of HESC.

Here, "F" of Futon cloth is used to distinguish from KOSHI and NUMERI for clothes defined by HESC. "KOSHI-F" includes KOSHI and HARI defined by HESC. The reason is as follows: At first, Futon cloth is used in body-lying state, and does not need HARI which is necessary mainly for men's summer suits. Secondly, experts of allied industry and distribution of Futon cloth could not discriminate between KOSHI and HARI. Further, Futon cloth with higher KOSHI has high HARI, and Futon cloth with larger HARI has large KOSHI. So, experts insisted that it was convenient to unify both terms into one primary hand. "NUMERI- $F$ " is defined as different from NUMERI by HESC. Futon cloth is, in general, finished with calendar treatment by resin to reduce air permeability. "NUMERI-F" of Futon cloth was defined as the primary hand of the fabric due to moist and sticky feeling when we touch with such a smooth surface treated by resin, for example, polyurethane resin.

There were numerous opinion among experts that NUMERI brought about from fine cashmere fibers was not necessary for Futon cloth. "GASATSUKI" is defined for the first time for Futon cloth in this paper.

This term is related to rather uncomfortable sound and/or feeling arisen when fabrics touch with other fabrics. It corresponds to KISHIMI defined for women's fine dress fabrics by HESC. However, KISHIMI means comfortable feeling caused by silk fabrics, and "GASATSUKI" gives the opposite effect on human being. Many experts insisted on the importance of "GASATSUKI" because there were a lot of cotton fabrics of high density in Futon cloths (ref. Table 1).

Terms concerning thermal and moisture transport properties as feeling and/or comfortability (frequency; $7 \%$ ), and appearance of fabrics as luster and/or drapability (5\%), are also described on questionnaires by the experts besides 5 primary hands.

\subsection{Subjective evaluation of primary hand values and total hand value of futon cloth}

Subjectively evaluated values of primary hands were obtained by 12 experts for 107 Futon cloth samples. The frequency distribution of the results followed nearly the normal distribution. Correlation coefficients between each panel were very high, and subjective values of primary hands agreed well for all primary hands. Correlation coefficients between mean values and those of each panel were very high (significance level: $0.1 \%$ ) for all primary hands, and so, the mean values were adopted as subjective values of primary hands. Correlation coefficients between each panel are shown in Tables 4 to 8 .

Correlation coefficients between each THV value evaluated by 12 experts are shown in Table 9 .

Although the coefficient between B (retailer) and other panels was a little small, the coefficient between B and the mean value of 12 experts was large (significance level; $0.1 \%$ ), and so, the mean value was adopted as the subjective value of THV. 
Table 4 Correlation Coefficients Between Each Panel for Evaluating SOFUTOSA of Futon Cloth*

\begin{tabular}{cccccccccccccc}
\hline \hline Panel & A & B & C & D & E & F & G & H & I & J & K & L & Mean \\
\hline A & 1.000 & 0.554 & 0.578 & 0.343 & 0.755 & 0.713 & 0.580 & 0.703 & 0.741 & 0.698 & 0.720 & 0.705 & 0.811 \\
B & & 1.000 & 0.729 & 0.535 & 0.700 & 0.749 & 0.839 & 0.619 & 0.610 & 0.617 & 0.745 & 0.706 & 0.844 \\
C & & & 1.000 & 0.421 & 0.791 & 0.762 & 0.700 & 0.746 & 0.565 & 0.697 & 0.753 & 0.701 & 0.863 \\
D & & & & 1.000 & 0.386 & 0.404 & 0.562 & 0.417 & 0.380 & 0.381 & 0.418 & 0.376 & 0.531 \\
E & & & & & 1.000 & 0.819 & 0.746 & 0.806 & 0.686 & 0.722 & 0.794 & 0.768 & 0.904 \\
F & & & & & & 1.000 & 0.714 & 0.704 & 0.702 & 0.715 & 0.816 & 0.698 & 0.891 \\
G & & & & & & 1.000 & 0.607 & 0.614 & 0.661 & 0.697 & 0.723 & 0.845 \\
H & & & & & & & & 1.000 & 0.619 & 0.640 & 0.734 & 0.690 & 0.826 \\
I & & & & & & & & 1.000 & 0.701 & 0.661 & 0.709 & 0.807 \\
J & & & & & & & & & 1.000 & 0.703 & 0.747 & 0.834 \\
K & & & & & & & & & & 1.000 & 0.775 & 0.885 \\
L & & & & & & & & & & & 1.000 & 0.866 \\
Mean & & & & & & & & & & & & 1.000 \\
\hline
\end{tabular}

$\cdot n=107 ; 0.1 \%$ significant level if $r>0.319$

Table 5 Correlation Coefficients Between Each Panel for Evaluating KOSHI-F of Futon Cloth*

\begin{tabular}{|c|c|c|c|c|c|c|c|c|c|c|c|c|c|}
\hline Panel & $\mathrm{A}$ & B & C & D & $\mathrm{E}$ & $F$ & G & $\mathrm{H}$ & I & $\mathrm{J}$ & $\mathrm{K}$ & $\mathrm{L}$ & Mean \\
\hline A & 1.000 & 0.613 & 0.509 & 0.551 & 0.488 & 0.553 & 0.535 & 0.664 & 0.632 & 0.549 & 0.286 & 0.287 & 0.720 \\
\hline B & & 1.000 & 0.499 & 0.781 & 0.671 & 0.727 & 0.718 & 0.709 & 0.661 & 0.750 & 0.501 & 0.490 & 0.867 \\
\hline C & & & 1.000 & 0.496 & 0.594 & 0.540 & 0.428 & 0.392 & 0.433 & 0.630 & 0.440 & 0.424 & 0.692 \\
\hline D & & & & 1.000 & 0.712 & 0.684 & 0.671 & 0.677 & 0.582 & 0.704 & 0.548 & 0.541 & 0.845 \\
\hline $\mathrm{E}$ & & & & & 1.000 & 0.664 & 0.671 & 0.579 & 0.526 & 0.766 & 0.580 & 0.627 & 0.837 \\
\hline F & & & & & & 1.000 & 0.746 & 0.636 & 0.546 & 0.702 & 0.562 & 0.561 & 0.846 \\
\hline G & & & & & & & 1.000 & 0.707 & 0.525 & 0.691 & 0.479 & 0.558 & 0.820 \\
\hline$F$ & & & & & & & & 1.000 & 0.536 & 0.613 & 0.310 & 0.444 & 0.776 \\
\hline I & & & & & & & & & 1.000 & 0.544 & 0.313 & 0.341 & 0.725 \\
\hline $\mathrm{J}$ & & & & & & & & & & 1.000 & 0.525 & 0.581 & 0.857 \\
\hline K & & & & & & & & & & & 1.000 & 0.661 & 0.654 \\
\hline L & & & & & & & & & & & & 1.000 & 0.694 \\
\hline Mean & & & & & & & & & & & & & 1.000 \\
\hline
\end{tabular}

Table 6 Correlation Coefficients Between Each Panel for Evaluating NUMERI-F of Futon Cloth*

\begin{tabular}{|c|c|c|c|c|c|c|c|c|c|c|c|c|c|}
\hline Panel & A & B & C & D & E & F & G & $\mathrm{H}$ & I & $\mathrm{J}$ & $\mathrm{K}$ & L & Mean \\
\hline A & 1.000 & 0.528 & 0.434 & 0.385 & 0.499 & 0.432 & 0.407 & 0.476 & 0.508 & 0.345 & 0.356 & 0.338 & 0.620 \\
\hline B & & 1.000 & 0.527 & 0.529 & 0.562 & 0.528 & 0.544 & 0.525 & 0.544 & 0.525 & 0.368 & 0.334 & 0.713 \\
\hline C & & & 1.000 & 0.590 & 0.558 & 0.589 & 0.534 & 0.555 & 0.535 & 0.448 & 0.348 & 0.343 & 0.703 \\
\hline D & & & & 1.000 & 0.628 & 0.637 & 0.629 & 0.595 & 0.660 & 0.546 & 0.514 & 0.414 & 0.781 \\
\hline $\mathrm{E}$ & & & & & 1.000 & 0.604 & 0.653 & 0.707 & 0.614 & 0.638 & 0.621 & 0.518 & 0.844 \\
\hline $\mathrm{F}$ & & & & & & 1.000 & 0.611 & 0.570 & 0.611 & 0.661 & 0.458 & 0.447 & 0.778 \\
\hline G & & & & & & & 1.000 & 0.618 & 0.591 & 0.676 & 0.600 & 0.619 & 0.824 \\
\hline $\mathrm{H}$ & & & & & & & & 1.000 & 0.619 & 0.518 & 0.504 & 0.383 & 0.788 \\
\hline I & & & & & & & & & 1.000 & 0.548 & 0.487 & 0.423 & 0.798 \\
\hline $\mathrm{J}$ & & & & & & & & & & 1.000 & 0.578 & 0.580 & 0.789 \\
\hline $\mathrm{K}$ & & & & & & & & & & & 1.000 & 0.601 & 0.710 \\
\hline L & & & & & & & & & & & & 1.000 & 0.666 \\
\hline Mean & & & & & & & & & & & & & 1.000 \\
\hline
\end{tabular}


Table 7 Correlation Coefficients Between Each Panel for Evaluating FUKURAMI of Futon Cloth*

\begin{tabular}{cccccccccccccc}
\hline \hline Panel & $\mathrm{A}$ & $\mathrm{B}$ & $\mathrm{C}$ & $\mathrm{D}$ & $\mathrm{E}$ & $\mathrm{F}$ & $\mathrm{G}$ & $\mathrm{H}$ & $\mathrm{I}$ & $\mathrm{J}$ & $\mathrm{K}$ & $\mathrm{L}$ & $\mathrm{Mean}$ \\
\hline $\mathrm{A}$ & 1.000 & 0.526 & 0.517 & 0.611 & 0.659 & 0.663 & 0.603 & 0.529 & 0.554 & 0.581 & 0.464 & 0.339 & 0.817 \\
$\mathrm{~B}$ & & 1.000 & 0.549 & 0.512 & 0.672 & 0.415 & 0.616 & 0.522 & 0.532 & 0.660 & 0.361 & 0.396 & 0.784 \\
C & & & 1.000 & 0.407 & 0.609 & 0.362 & 0.504 & 0.586 & 0.423 & 0.523 & 0.300 & 0.221 & 0.705 \\
D & & & & 1.000 & 0.472 & 0.493 & 0.548 & 0.361 & 0.341 & 0.545 & 0.471 & 0.441 & 0.695 \\
E & & & & & 1.000 & 0.491 & 0.512 & 0.663 & 0.624 & 0.646 & 0.366 & 0.271 & 0.814 \\
F & & & & & & 1.000 & 0.548 & 0.393 & 0.411 & 0.532 & 0.235 & 0.289 & 0.663 \\
G & & & & & & & 1.000 & 0.448 & 0.453 & 0.610 & 0.376 & 0.387 & 0.757 \\
H & & & & & & & & 1.000 & 0.637 & 0.599 & 0.375 & 0.273 & 0.748 \\
I & & & & & & & & & 1.000 & 0.516 & 0.301 & 0.208 & 0.695 \\
J & & & & & & & & & 1.000 & 0.326 & 0.331 & 0.795 \\
K & & & & & & & & & & 1.000 & 0.638 & 0.483 \\
L & & & & & & & & & & & 1.000 & 0.441 \\
Mean & & & & & & & & & & & & 1.000 \\
\hline
\end{tabular}

$\cdot n=107 ; 0.1 \%$ significant level if $r>0.319,1 \%$ if $r>0.249,5 \%$ if $r>0.189$

Table 8 Correlation Coefficients Between Each Pantel for Evaluating GASATSU.

KI of Futon Cloth*

\begin{tabular}{cccccccccccccc}
\hline \hline Panel & $\mathrm{A}$ & $\mathrm{B}$ & $\mathrm{C}$ & $\mathrm{D}$ & $\mathrm{E}$ & $\mathrm{F}$ & $\mathrm{G}$ & $\mathrm{H}$ & $\mathrm{I}$ & $\mathrm{J}$ & $\mathrm{K}$ & $\mathrm{L}$ & Mean \\
\hline A & 1.000 & 0.651 & 0.636 & 0.563 & 0.687 & 0.708 & 0.544 & 0.702 & 0.592 & 0.684 & 0.586 & 0.584 & 0.819 \\
B & & 1.000 & 0.590 & 0.541 & 0.693 & 0.685 & 0.723 & 0.790 & 0.702 & 0.672 & 0.566 & 0.701 & 0.864 \\
C & & & 1.000 & 0.491 & 0.748 & 0.615 & 0.353 & 0.644 & 0.627 & 0.545 & 0.550 & 0.580 & 0.766 \\
D & & & & 1.000 & 0.552 & 0.529 & 0.615 & 0.606 & 0.483 & 0.665 & 0.528 & 0.449 & 0.724 \\
E & & & & & 1.000 & 0.733 & 0.509 & 0.699 & 0.675 & 0.601 & 0.508 & 0.690 & 0.842 \\
F & & & & & & 1.000 & 0.656 & 0.729 & 0.688 & 0.700 & 0.593 & 0.595 & 0.852 \\
G & & & & & & & 1.000 & 0.725 & 0.599 & 0.674 & 0.566 & 0.487 & 0.770 \\
H & & & & & & & & 1.000 & 0.676 & 0.692 & 0.727 & 0.656 & 0.892 \\
I & & & & & & & & & 1.000 & 0.636 & 0.541 & 0.598 & 0.803 \\
J & & & & & & & & & 1.000 & 0.658 & 0.492 & 0.823 \\
K & & & & & & & & & & 1.000 & 0.502 & 0.748 \\
L & & & & & & & & & & & 1.000 & 0.763 \\
Mean & & & & & & & & & & & & 1.000 \\
\hline
\end{tabular}

$\cdot n=107 ; 0.1 \%$ significant level if $r>0.319$

Table 9 Correlation Coefficients Between Each Panel for Evaluating THV of Futon Cloth*

\begin{tabular}{cccccccccccccc}
\hline \hline Panel & $\mathrm{A}$ & $\mathrm{B}$ & $\mathrm{C}$ & $\mathrm{D}$ & $\mathrm{E}$ & $\mathrm{F}$ & $\mathrm{G}$ & $\mathrm{H}$ & $\mathrm{I}$ & $\mathrm{J}$ & $\mathrm{K}$ & $\mathrm{L}$ & Mean \\
\hline $\mathrm{A}$ & 1.000 & 0.267 & 0.463 & 0.501 & 0.458 & 0.546 & 0.389 & 0.471 & 0.433 & 0.627 & 0.544 & 0.591 & 0.681 \\
$\mathrm{~B}$ & & 1.000 & 0.214 & 0.142 & 0.194 & 0.255 & 0.191 & 0.198 & 0.142 & 0.476 & 0.324 & 0.238 & 0.417 \\
C & & & 1.000 & 0.700 & 0.550 & 0.640 & 0.610 & 0.725 & 0.754 & 0.565 & 0.659 & 0.648 & 0.826 \\
$\mathrm{D}$ & & & & 1.000 & 0.543 & 0.711 & 0.552 & 0.711 & 0.610 & 0.437 & 0.542 & 0.682 & 0.787 \\
E & & & & & 1.000 & 0.594 & 0.664 & 0.560 & 0.580 & 0.545 & 0.553 & 0.621 & 0.740 \\
F & & & & & & 1.000 & 0.589 & 0.703 & 0.595 & 0.512 & 0.670 & 0.723 & 0.817 \\
G & & & & & & & 1.000 & 0.610 & 0.722 & 0.580 & 0.655 & 0.602 & 0.783 \\
H & & & & & & & & 1.000 & 0.673 & 0.490 & 0.644 & 0.655 & 0.820 \\
I & & & & & & & & & 1.000 & 0.613 & 0.636 & 0.633 & 0.805 \\
J & & & & & & & & & 1.000 & 0.665 & 0.599 & 0.775 \\
K & & & & & & & & & & 1.000 & 0.711 & 0.827 \\
L & & & & & & & & & & & 1.000 & 0.842 \\
Mean & & & & & & & & & & & & & \\
\hline
\end{tabular}




\subsection{Objective evaluation of primary hands and total hand of futon cloth}

\subsubsection{Objective evaluation equation for primary} hand values

Stepwise block residual regressions by mechanical parameters are shown in Figs. 3 to 7 for primary hands "SOFUTOSA", $\quad$ "KOSHI-F", $\quad$ "NUMERI-F", "FUKURAMI" and "GASATSUKI". Regression accuracy is shown by the correlation coefficient $(R)$ between subjective and objective values. The coefficient increases as the repetition of regression. "SOFUTOSA" is affected by the order of shearing property, bending property and surface property. Bending property affects mostly to "KOSHI-F" and shearing property comes next. "NUMERI-F" is dominated mainly by surface property. "FUKURAMI" is controlled by the order of surface property, thickness and weight, tensile property, and compressional property. "GASATSUKI" is influenced by the order of shearing property, tensile property, and surface property.

Coefficients of final equation (5) obtained here (named DM-02) are shown in Table 10 together with means and standard deviations of mechanical parameters.

Some parameters are transformed into logarithms to get symmetrical distribution around their mean values.

Correlation coefficients and regression errors (root mean square) are shown in Table 11. It is clearly shown that the coefficients are large and the errors are small for all primary hands, especially in "SOFUTOSA", "KOSHI-F", and "GASATSUKI". Mean standard deviations of subjective values of 12 experts are also shown in Table 11. Regression errors by objective evaluation are smaller than by subjective evaluation, and the regression accuracy is very high. Correlations between subjective and objective values of each primary hand are shown in Figs 8 to 12 .

\subsubsection{Objective evaluation equation for total hand value}

Stepwise block residual regression by 5 primary hands, air resistance, and water regain, is shown in Fig.13. Regression accuracy shown by the correlation coefficient between subjective and objective values increases as the repetition of regression. THV of Futon cloth is strongly dominated by "SOFUTOSA", and then comes water regain, "FUKURAMI", and "KOSHI-F". However, the effects of "GASATSUKI", air resistance, and "NUMERI-F" are extremely small.

Although the accuracy between "GASATSUKI" and regressed values is high as next to "SOFUTOSA" at the 1st step of stepwise regression, it is low in the 2nd step.

The reason is explained by high inverse correlation between "SOFUTOSA" and "GASATSUKI" $(\mathrm{R}=-0.9)$, that is, the problem of multi-collinearity is solved by stepwise regression.

Coefficients of final equation (7) obtained here (named DM-11) are shown in Table 12 together with means and standard deviations of primary hands. Correlations between subjective and objective values are shown in Fig.14.

\section{Discussion}

\subsection{Objective evaluation equation of primary hand values}

Objective evaluation equations of primary hands defined by experts of Futon cloth are derived from the mechanical parameters of Futon cloth by stepwise residual regression method, and those equations (DM-02) showed high accuracy with small errors. In regard to contribution of mechanical property on primary hand, shearing property, bending property, surface property and shearing property appeared in the 1st block of "SOFUTOSA", "KOSHI-F", "NUMERI-F" and "GASATSUKI", respectively. This is expected results. However, first, surface property, next, thickness and weight, and then tensile property have influence on "FUKURAMI", and the contribution of compressional property to "FUKURAMI" was small (ref. Fig.6). Some experts insisted that they evaluated "FUKURAMI" of Futon cloth by the feeling of softness in compression and bulkiness as the definition says (ref. Table 3), and had not evaluated by the feeling of surface property.

Variation of subjective evaluation of "FUKURAMI" is larger than that of other primary hands (ref. Table 11), and evaluation of "FUKURAMI" seems very difficult even by experts. As Futon cloth is thinner than men's suit fabrics, subjective evaluation is more difficult. In the 1st step of Fig.6, correlation coefficient is in the order of surface property, tensile property, shearing property, and thickness and weight. But thickness and weight plays important parts at the 2nd step. This is caused by multi-collinearity between each mechanical block, and the correlation between surface property and tensile property is larger than that between surface property and thickness and weight. If surface property is decided as the 1st block, the related part is excluded from the residue. Therefore, mutual relationship between each mechanical property could be made clear by the stepwise block residual regression method.

\subsection{Objective evaluation equation of total hand value}

Objective evaluation equation of THV (DM-11) is derived from 5 primary hands evaluated objectively, 


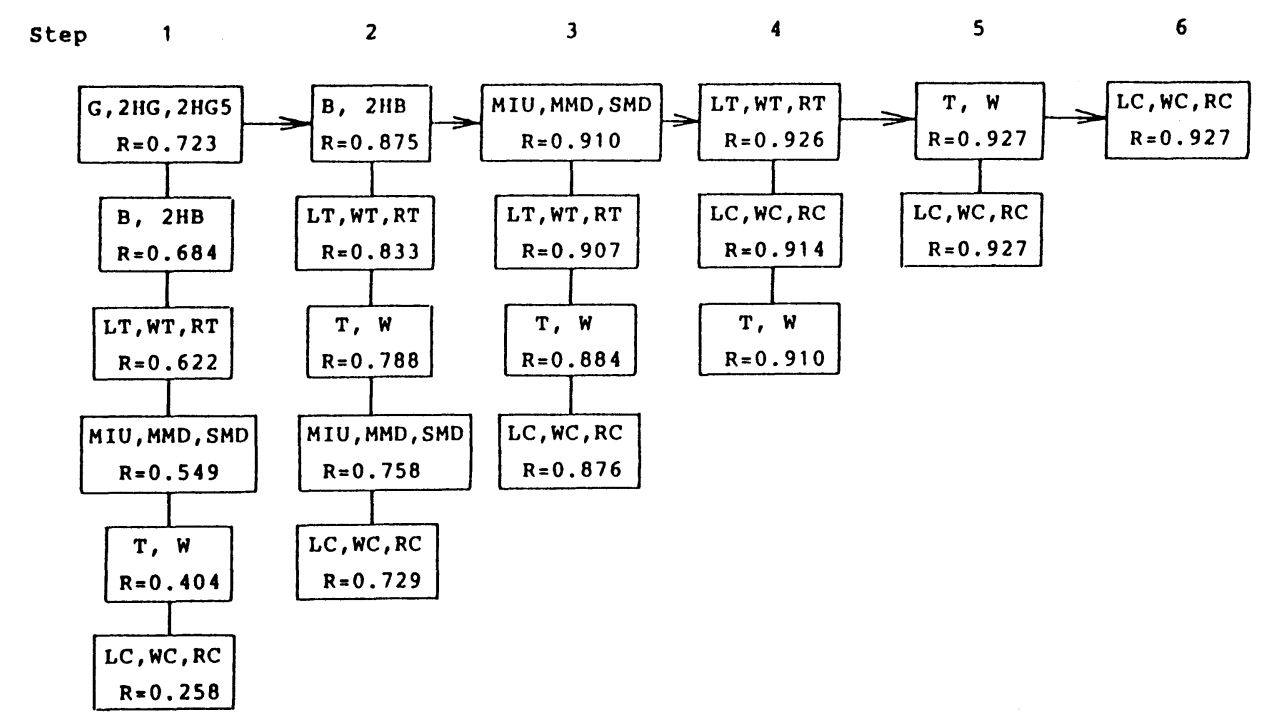

Fig. 3 Stepwise block residual regression for the analysis of Primary Hand "SOFUTOSA".

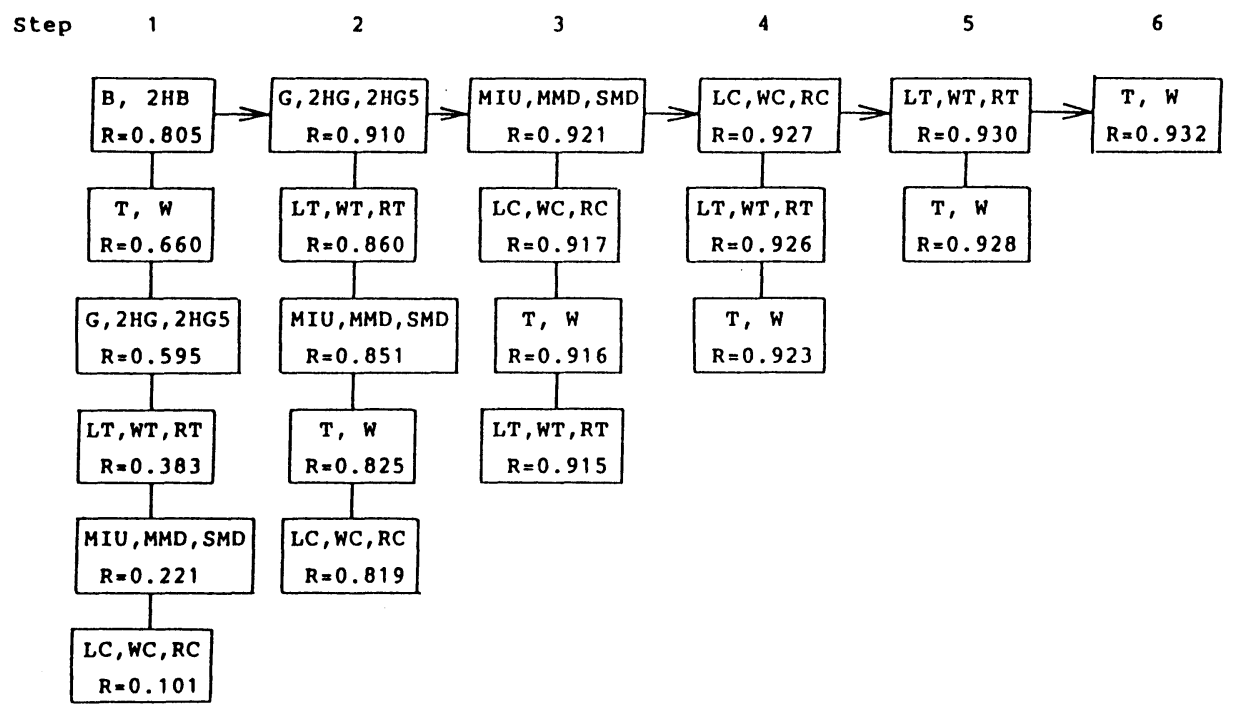

Fig. 4 Stepwise block residual regression for the analysis of Primary Hand "KOSHI-F".

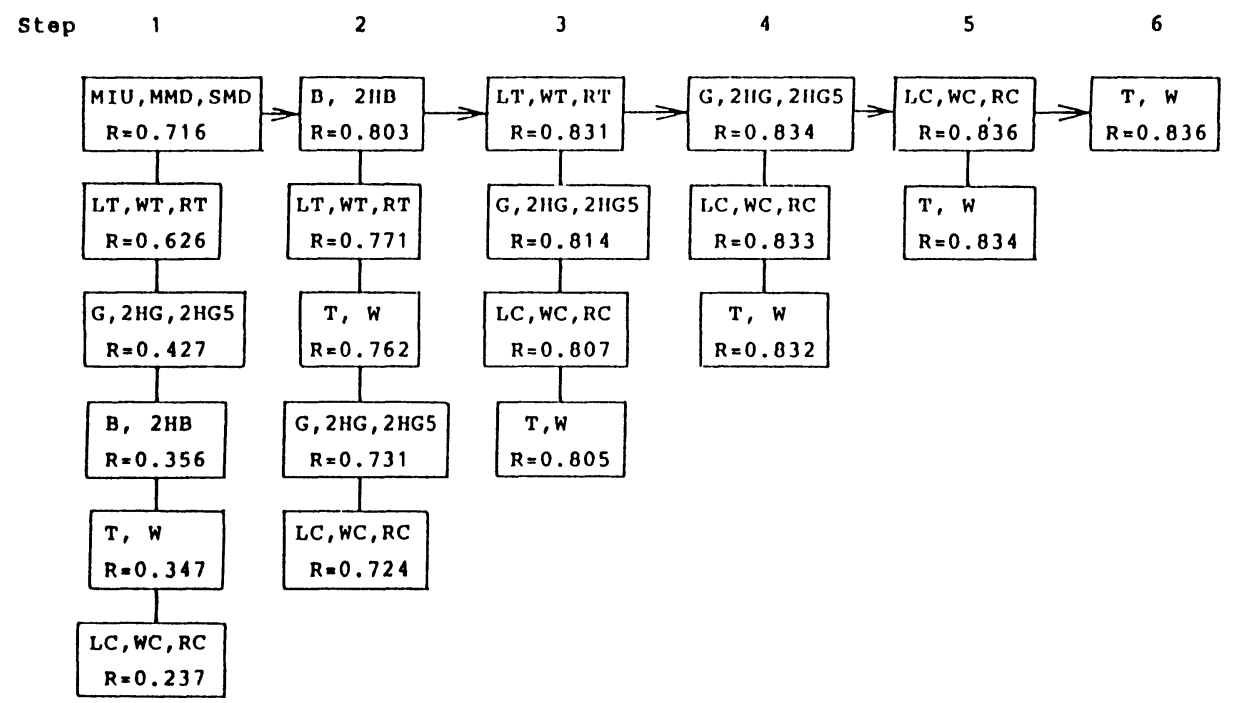

Fig. 5 Stepwise block residual regression for the analysis of Primary Hand "NUMERI-F". 


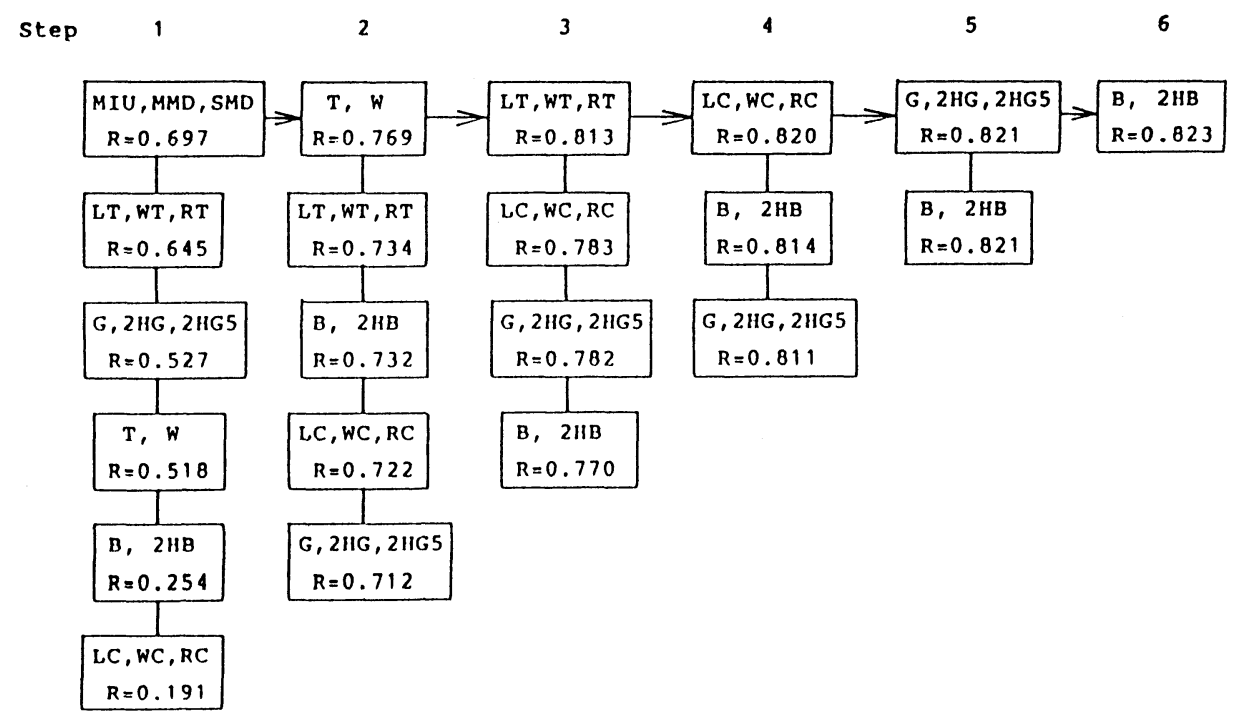

Fig. 6 Stepwise block residual regression for the analysis of Primary Hand "FUKURAMI".

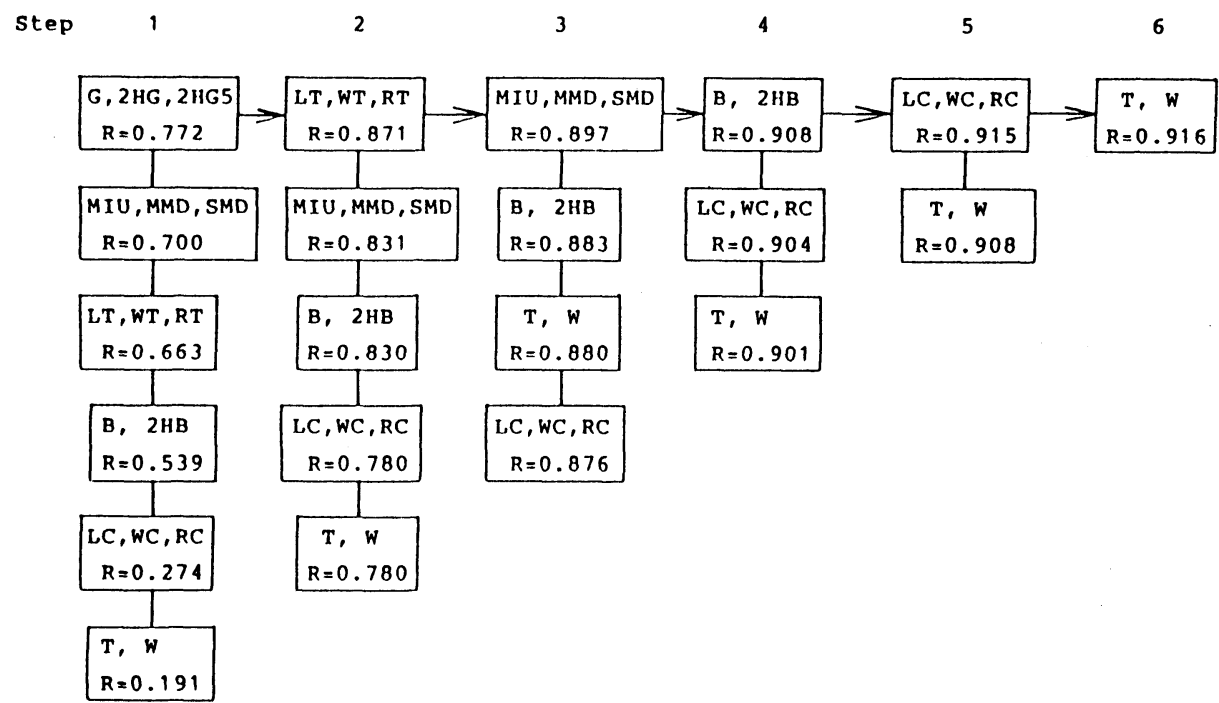

Fig. 7 Stepwise block residual regression for the analysis of Primary

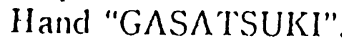

Table 10 Mechanical Parameters and Coefficients for DM-02 Equation Used for Objective Evaluation of Primary Hand of Futon Cloth

\begin{tabular}{|c|c|c|c|c|c|c|c|c|c|c|c|c|c|c|c|}
\hline \multirow[t]{2}{*}{ Block } & \multirow[b]{2}{*}{$\mathrm{i}$} & \multirow{2}{*}{\multicolumn{2}{|c|}{ Parameterty }} & \multirow{2}{*}{$\begin{array}{c}\text { Mean } \\
\mathrm{X}_{1} \\
\end{array}$} & \multirow[t]{2}{*}{ S. D. } & \multicolumn{2}{|c|}{ SOFUTOSA } & \multicolumn{2}{|c|}{ KOSHI.F } & \multicolumn{2}{|c|}{ NUMERI-F } & \multicolumn{2}{|c|}{ FUKURAMI } & \multicolumn{2}{|c|}{ GASATSUKI } \\
\hline & & & & & & $\mathrm{i}$ & $C_{1}$ & $\mathrm{i}$ & $C_{1}$ & $\mathrm{i}$ & $C_{1}$ & $\mathrm{i}$ & $C_{1}$ & $\mathrm{i}$ & $\mathrm{C}_{i}$ \\
\hline & 0 & & & & & 0 & 4.4028 & 0 & 5.0280 & 0 & 5.0215 & 0 & 4.4776 & 0 & 5.0234 \\
\hline \multirow{3}{*}{1} & 1 & & LT & 0.6848 & 0.0494 & 6 & -1.4701 & 4 & 0.8696 & 12 & -0.2830 & 12 & 0.4189 & 6 & 1.7118 \\
\hline & 2 & $\log$ & WT & 0.8084 & 0.1117 & 7 & -0.6265 & 5 & 0.7047 & 13 & -0.0147 & 13 & -0.8658 & 7 & 0.5743 \\
\hline & 3 & & $\mathrm{RT}$ & 50.0617 & 5.7249 & 8 & 0.7338 & 6 & 1.6299 & 14 & -1.2405 & 14 & -0.4546 & 8 & -0.8761 \\
\hline \multirow{2}{*}{2} & 4 & $\log$ & $\mathrm{B}$ & -1.1491 & 0.1436 & 4 & -1.2073 & 7 & -0.4209 & 4 & -0.8679 & 15 & 0.2567 & 1 & 0.4572 \\
\hline & 5 & $\log$ & $2 \mathrm{HB}$ & -1.1672 & 0.1722 & 5 & 0.2999 & 8 & -0.8217 & 5 & 0.2412 & 16 & 0.3598 & 2 & -0.5463 \\
\hline \multirow{3}{*}{3} & 6 & $\log$ & G & 0.3969 & 0.1845 & 12 & -0.0927 & 12 & 0.1059 & 1 & -0.0368 & 1 & -0.3091 & 3 & 0.4194 \\
\hline & 7 & $\log$ & $2 \mathrm{HG}$ & 0.5945 & 0.2144 & 13 & 0.0141 & 13 & 0.2761 & 2 & -0.2624 & 2 & -0.1422 & 12 & 0.1690 \\
\hline & 8 & $\log$ & 2HG5 & 0.9105 & 0.1502 & 14 & -0.4526 & 14 & -0.3988 & 3 & -0.4315 & 3 & -0.3187 & 13 & -0.2746 \\
\hline \multirow{3}{*}{4} & 9 & & LC* & 0.6261 & 0.0423 & 1 & 0.0390 & 9 & 0.1125 & 6 & 0.0079 & 9 & -0.1717 & 14 & 0.5061 \\
\hline & 10 & $\log$ & WC* & -1.6844 & 0.1422 & 2 & 0.1211 & 10 & -0.1091 & 7 & -0.1234 & 10 & 0.0984 & 4 & 0.3038 \\
\hline & 11 & & $\mathrm{RC}$ & 56.8907 & 7.0653 & 3 & -0.2617 & 11 & 0.1244 & 8 & 0.0277 & 11 & -0.0977 & 5 & -0.0528 \\
\hline \multirow{3}{*}{5} & 12 & & MIU & 0.1177 & 0.0114 & 15 & -0.1230 & 1 & -0.0072 & 9 & 0.0369 & 6 & 0.1728 & 9 & 0.2188 \\
\hline & 13 & $\log$ & MMD & -1.9834 & 0.1813 & 16 & 0.1390 & 2 & 0.1368 & 10 & -0.0665 & 7 & 0.0711 & 10 & -0.2544 \\
\hline & 14 & $\log$ & SMD & 0.2130 & 0.1454 & 9 & -0.0578 & 3 & 0.1479 & 11 & -0.1323 & 8 & -0.3302 & 11 & -0.1255 \\
\hline \multirow{2}{*}{6} & 15 & $\log$ & $T$ & -0.5357 & 0.0892 & 10 & 0.0994 & 15 & -0.1373 & 15 & -0.0568 & 4 & -0.0434 & 15 & 0.0660 \\
\hline & 16 & $\log$ & W & 1.1317 & 0.0706 & 11 & 0.0024 & 16 & 0.0577 & 16 & 0.0603 & 5 & 0.1159 & 16 & -0.0632 \\
\hline
\end{tabular}


Table 11 Correlation Coefficients (R) and Regression Errors (RMS) Between Objective and Subjective Evaluation of Fabric Hand of Futon Cloth

\begin{tabular}{lcccccc}
\hline & & SOFUTOSA & KOSHI-F & NUMERI-F & FUKURAMI & GASATSUKI \\
\hline \multirow{2}{*}{ DM-02 } & R & 0.927 & 0.932 & 0.836 & 0.823 & 0.916 \\
& RMS & 0.743 & 0.680 & 1.029 & 1.052 & 0.793 \\
\hline \multirow{2}{*}{ Mean Stand. Dev. } & 1.490 & 1.687 & 1.393 & 1.854 & 1.484 \\
\hline
\end{tabular}

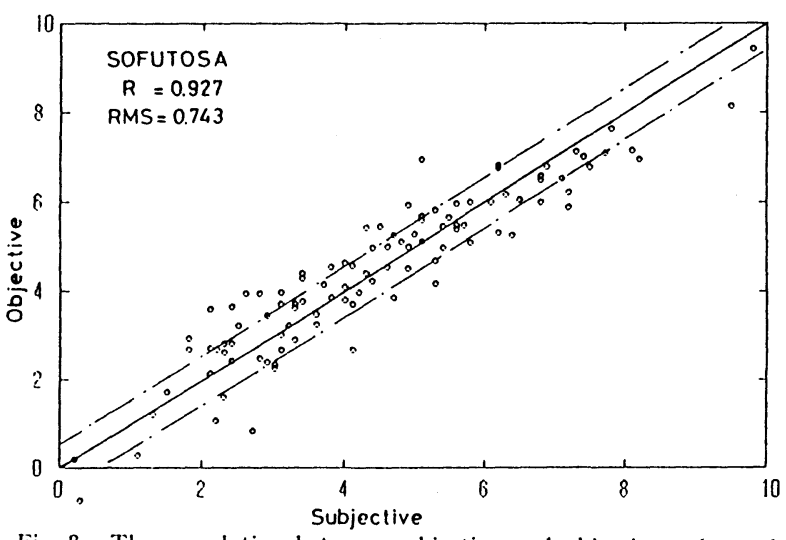

Fig. 8 The correlation between subjective and objective values of Futon cloth Primary Hand "SOFUTOSA" calculated from equation DM-02.

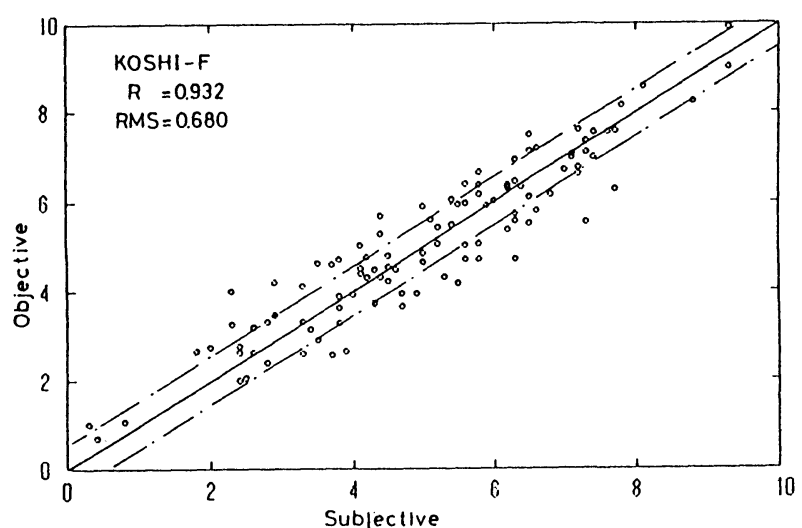

Fig. 9 The correlation between subjective and objective values of Futon cloth Primary Iland "KOSHI-F" calculated from equa. tion DM.02.

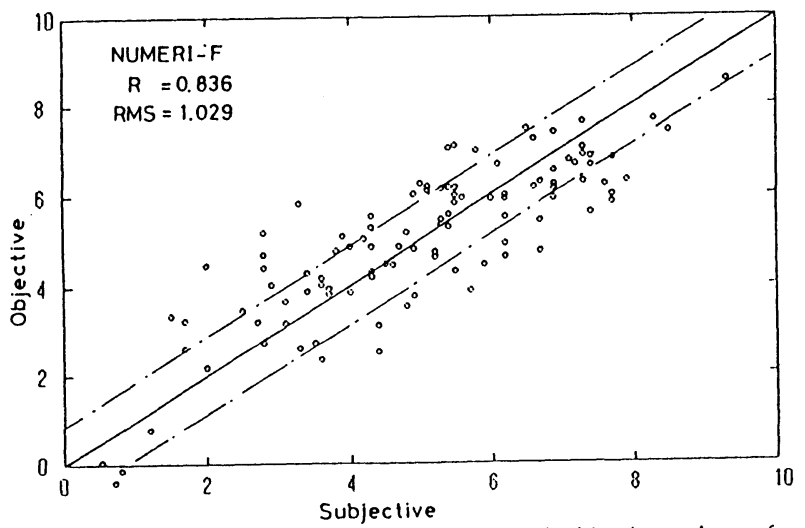

Fig. 10 The correlation between subjective and objective values of Futon cloth Primary Hand "NUMERI-F" calculated from equation DM-02.

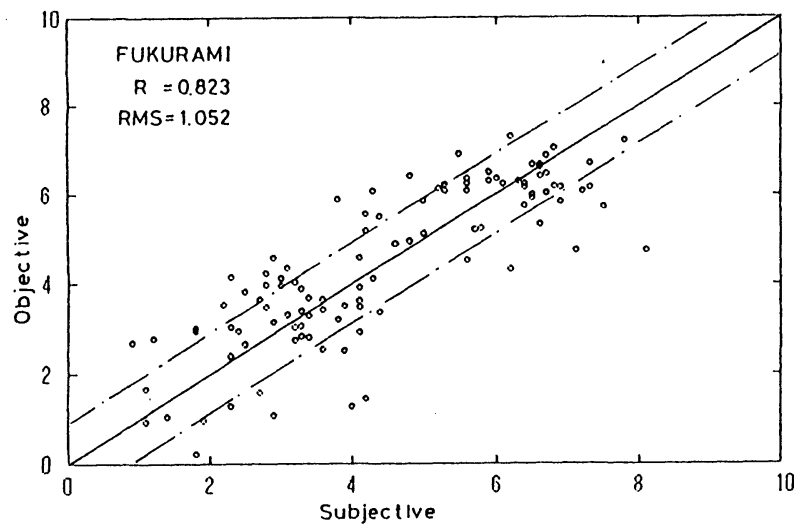

Fig. 11 The correlation between subjective and objective values of Futon cloth Primary Hand "FUKURAMI" calculated from equation DM.02.

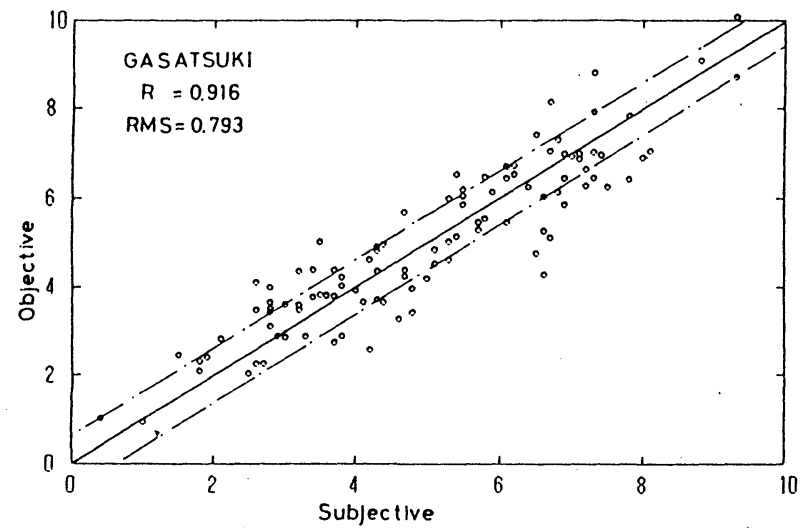

Fig. 12 The correlation between subjective and objective values of Futon cloth Primary Hand "GASATSUKI" calculated from equation DM.02.

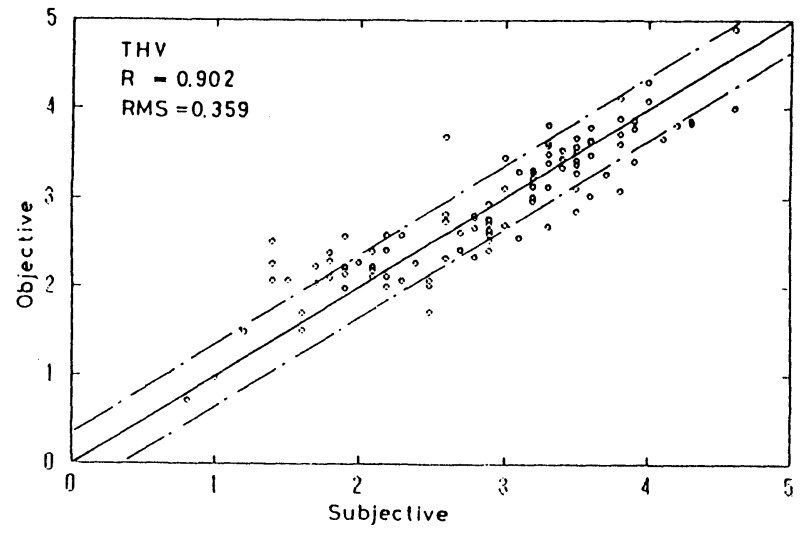

Fig. 14 The correlation betwecn subjective and objective values of futon cloth Total Hand Value calculated from equation DM.11 


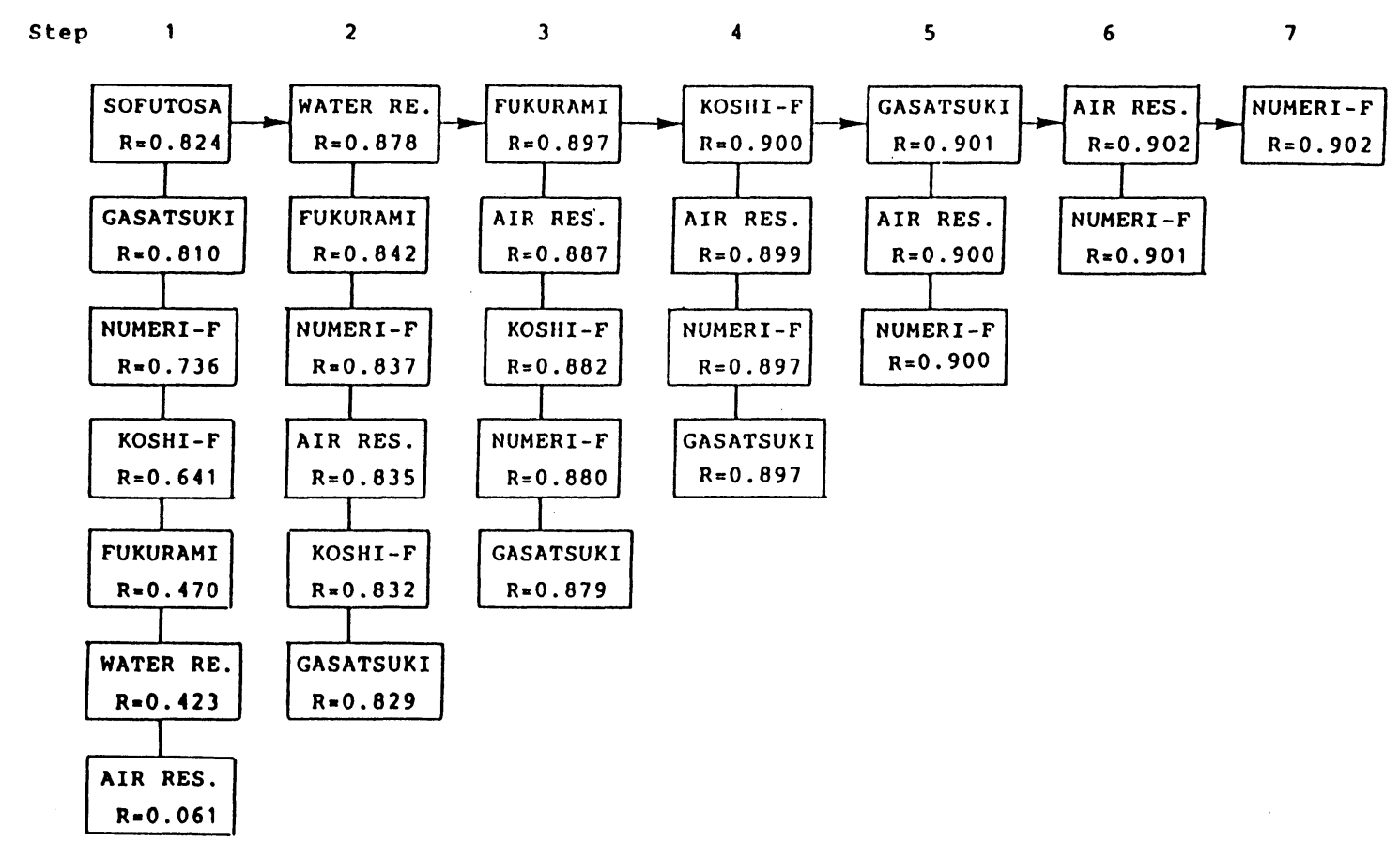

Fig. 13 Stepwise block residual regression for the analysis of Total Hand Value of Futon cloth.

Table 12 Primary Hand Values and Coefficients for DM-11 Equation Used for Objective Evaluation of THV of Futon Cloth

\begin{tabular}{llcccccc}
\hline \hline $\mathrm{i}$ & \multicolumn{1}{c}{$\mathrm{Y}_{1}$} & $\mathrm{C}_{11}$ & $\mathrm{C}_{21}$ & $\overline{Y_{1}}$ & $\overline{Y_{1}{ }^{2}}$ & $\sigma_{11}$ & $\sigma_{21}$ \\
\hline 1 & SOFUTOSA & 0.6035 & 0.0858 & 4.4032 & 23.0668 & 1.9180 & 16.3196 \\
2 & KOSHI.F & 0.1623 & -0.1136 & 5.0288 & 28.4811 & 1.7867 & 18.5645 \\
3 & NUMERI-F & -0.0319 & 0.0144 & 5.0215 & 28.0147 & 1.6731 & 15.0368 \\
4 & FUKURAMI & -0.6571 & 0.7045 & 4.4283 & 22.6690 & 1.7490 & 14.7355 \\
5 & GASATSUKI & -0.1434 & 0.1237 & 5.0236 & 28.8327 & 1.8965 & 21.3372 \\
6 & AIR RES. & 0.0424 & -0.0101 & 9.1065 & 102.485 & 4.4223 & 96.6415 \\
7 & WATER RE. & 0.9811 & -0.9569 & 8.3449 & 72.0343 & 1.5484 & 22.0296 \\
\hline \multicolumn{2}{l}{ C $_{00}=2.8907$} & & & & & &
\end{tabular}

together with air resistance and water regain. Here, contribution of each primary hand to THV will be investigated. Equ.(7) is substituted as follows:

$$
\begin{aligned}
& T H V=C_{00}+\sum_{i=1}^{7} Z_{i} \\
& Z_{i}=C_{1 i} \frac{Y_{i}-\bar{Y}_{i}}{\sigma_{i}}+C_{2 i} \frac{Y_{i}^{2}-\overline{Y_{i}^{2}}}{\sigma_{2 i}}
\end{aligned}
$$

Among 7 parameters of this equation, only one primary hand is changed under constant values (mean value of the population) of 6 parameters, and the result obtained is shown in Fig.15. For example, solid line "SOFUTOSA" is drawn under constant mean values of other primary hands, air resistance and water regain.
"SOFUTOSA" affects strongly to $Z_{\text {i }}$, namely THV. If "SOFUTOSA" is the larger, THV becomes the higher in the range of this figure. Although the effect of "KOSHI-F" is very small, it decreases THV at small value of "KOSHI-F". There is such region (at about 3.9 of primary hand value) as "FUKURAMI" minimizes THV. "NUMERI-F" has no effect, and "GASATSUKI" has almost no effect on THV.

The effect of air resistance and water regain is shown in Fig.16. Although air resistance has little effect on THV, the larger the air resistance, the higher THV becomes. Optimum point is clearly shown for water regain between 6 to $9 \%$. It lowers THV greatly at larger and/or smaller value.

Air resistance and water regain are adopted as the corresponding indices of thermal insulation value and comfortability, respectively. However, these parameters are not necessarily adequate indices. 


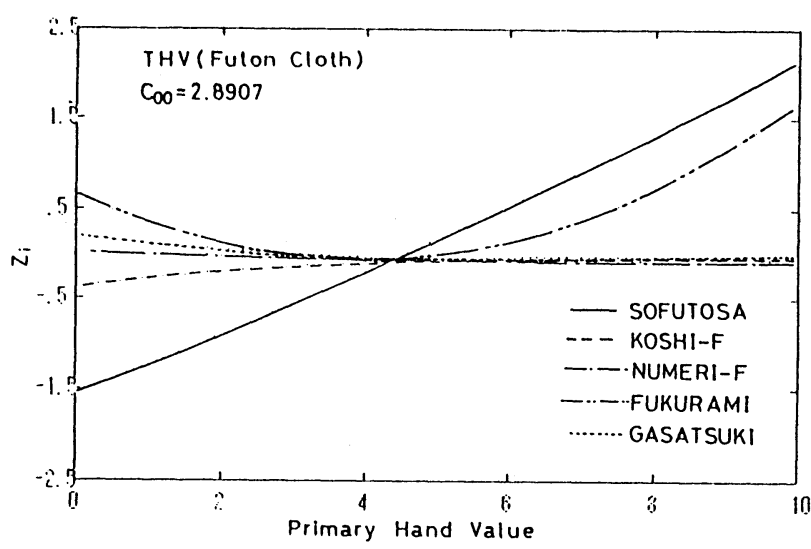

Fig. 15 The contribution of each Primary Hand to Total Hand Value of Futon cloth.

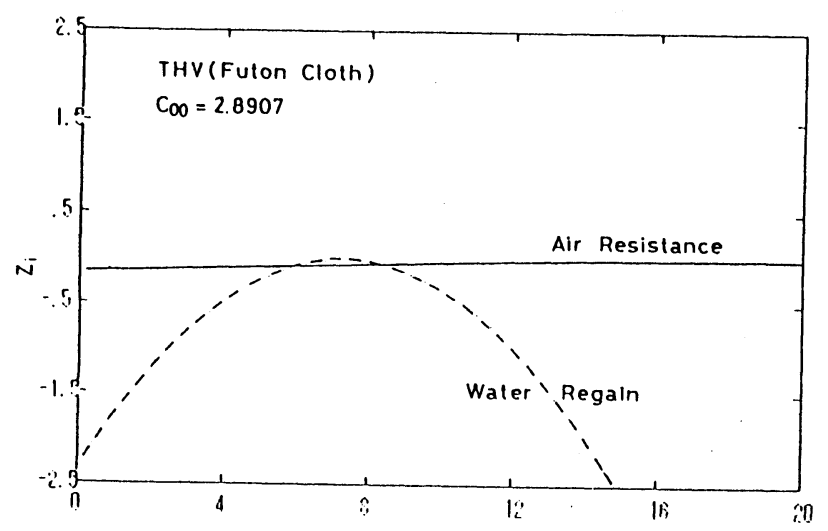

Fig. 16 The contribution of air resistance and water regain to Total II and Value of Futon cloth.

For example, such values were studied as q-max (warm-cool feeling when touching fabrics, which gives cool feeling when the value is larger), apparent thermal conductivity of fabric, and heat keeping ratio through fabric measured by Thermo-Labo-II $\left[\begin{array}{lll}1 & 1 & 1\end{array}\right]$. However, as these parameters are affected very much by operator's experience and measuring conditions (temperature, relative humidity, wind velocity), it was not so easy to get reliable results at a short time. Therefore, those parameters could not be adopted. Measurement of the amount of air by Fragile method is obligated for production and sales of Futon cloth now, and so air resistance which could easily be measured was adopted as the parameter of thermal insulation value of Futon cloth. Adequate parameter could not be found for the index of comfortability, and there was no choice but to adopt water regain. These parameters should be investigated precisely in the future.

In the 1st step of the regression of THV, regression accuracy was very high $(\mathrm{R}>0.8)$ with "SOFUTOSA" and with "GASATSUKI". This means that THV could be estimated well with only one primary hand. Futon cloth having higher "SOFUTOSA" or having lower "GASATSUKI" could be judged to have higher THV.

Each value is useful to obtain rough evaluation of THV.

Thirty samples of new Futon cloth were evaluated objectively by the equations developed this time (DM-02, DM-11), and these samples were also evaluated subjectively by the experts. Correlations of both evaluations were very high $(\mathrm{R}>0.9)$ for all primary hands and THV. So, availability of the equations was confirmed, and the usefulness of objective evaluation method was clearly shown.

\subsection{Subjective evaluation by consumers}

In order to find out the characteristics of hand evaluation of Futon cloth by consumers, the same analysis mentioned above was carried out using subjectively evaluated values by consumers. 10 housewives aged from 30 to 60 were chosen as panels of consumers. They were familiar with Futon cloth over 20 years at least.

Subjective evaluations of primary hands and THV by consumers agreed very well (significance level; 0.1 \%) with each other. However, the correlation coefficients were a little smaller than those of experts. Correlation coefficients of mean values of primary hands between consumers and experts are shown in Table 13. Correlation between consumers and experts is very high (significance level; 0.1\%). Using the subjective values by consumers, objective evaluation equations were derived by the stepwise residual regression method mentioned above. It was found that consumers evaluated primary hand "SOFUTOSA" mainly by bending property, unlike to shearing property by experts. Experts thought the degree of "SOFUTOSA" for the evaluation of THV first of all, but, consumers judged the degree of "GASATSUKI" first of all. After all, the objective evaluation equations derived from subjective evaluation of experts was shown widely usable for objective evaluation of primary hands and THV (DM-02, DM-11, respectively) of Futon cloth.

\section{Conclusions}

In order to evaluate fabric hand of Futon cloth objectively, primary hands for Futon cloth were selected and defined by experts who engaged in allied industry and distribution of Futon cloth. On the basis of subjective data by the experts, objective evaluation equations for primary hands and Total Hand Value (THV) were derived by the method of stepwise block residual regression using the mechanical parameters of Futon cloth. Following conclusions are summarized:

(1) Five primary hands such as; "SOFUTOSA", "KOSHI-F", "NUMERI-F", "FUKURAMI" and "GASATSUKI" were defined for Futon cloth.

(2) Objective evaluation equations of primary hands (DM-02) were developed with high accuracy and with 
Table 13 Correlation coefficients between consumersand expertsfor evaluating primary hand of Futon cloth

\begin{tabular}{|c|c|c|c|c|c|c|c|c|c|c|}
\hline Primary Hand & $C-S$ & $\mathrm{C}-\mathrm{K}$ & $C-N$ & $C-F$ & $C-G$ & $E-S$ & $E-K$ & $E-N$ & $E-F$ & $E-G$ \\
\hline Con-SOFUTOSA & 1.000 & -0.903 & 0.505 & 0.182 & -0.879 & 0.906 & -0.845 & 0.601 & 0.267 & -0.857 \\
\hline Con-KOSHI-F & & 1.000 & -0.392 & -0.065 & 0.833 & -0.854 & 0.887 & -0.532 & -0.154 & 0.780 \\
\hline Con-NUMERI-F & & & 1.000 & 0.763 & -0.679 & 0.666 & -0.314 & 0.708 & 0.688 & -0.733 \\
\hline Con-FUKURAMI & & & & 1.000 & -0.419 & 0.301 & -0.033 & 0.381 & 0.833 & -0.483 \\
\hline Con-GASATSUKI & & & & & 1.000 & -0.910 & 0.734 & -0.693 & -0.434 & 0.894 \\
\hline Exp-SOFUTOSA & & & & & & 1.000 & -0.808 & 0.707 & 0.404 & -0.928 \\
\hline Exp-KOSHI-F & & & & & & & 1.000 & -0.445 & -0.164 & 0.699 \\
\hline Exp-NUMERI-F & & & & & & & & 1.000 & 0.408 & -0.681 \\
\hline Exp-FUKURAMI & & & & & & & & & 1.000 & -0.547 \\
\hline Exp-GASATSUKI & & & & & & & & & & 1.000 \\
\hline
\end{tabular}

$n=107 ; 0.1 \%$ significant level if $R>0.319,1 \%$ if $R>0.249,5 \%$ if $R>0.189$

small errors.

(3) Objective evaluation equation of THV (DM-11) was developed from seven parameters, namely, five primary hands, air resistance and water regain.

\section{Acknowledgment}

We want to express our hearty thanks to the people who co-operated in the definition of primary hands for Futon cloth; mainly engineers in finishing, engineering, sales, distribution of Daiwabo Co.

\section{References}

[1] S. Kawabata; "The Standardization and Analysis of Hand Evaluation, 2nd ed.", Hand Evaluation and Standardization Committee, Text. Mach. Soc. Japan, Osaka, (1980).

[2] S. Kawabata, M. Niwa; J. Text. Inst., 80(1), 19 (1989).

[3] S. Kawabata; "Objective Evaluation Method of Clothing Fabrics and Its Application", Text. Mach. Soc. Japan, Osaka, p.1 (1986).
[4] S. Kawabata; "Basic Course of Fibrous Materials in Kyoto, (1st) Mechanical Characteristics and Fabric Hand of Clothing Fabrics", Fibrous Materials Research Group, p.9 (1988).

[5] S. Kawabata; J. Text MAch. Soc. Japan, 26(10), P721 (1973).

[6] M. Matsudaira, S. Kawabata, M. Niwa; J. Text. Mach. Soc. Japan, 37(4), T49 (1984).

[7] S. Kawabata, M. Niwa; J. Text. Mach. Soc. Japan, 37(7), T113 (1984).

[8] M. Kendall; "Multivariate Analysis, 2nd ed.", Charles Griffin, London, p.95 (1980).

[9] S. Kawabata; J. Text. Mach. Soc. Japan, 40(6), T59 (1987).

[10] The Soc. Fiber Sci. Tech. ed.; "Sen-i Binran, Raw Materials", p.966, Maruzen (1968).

[11] S. Kawabata; J. Text. Mach. Soc. Japan, 37(8), T130 (1984). 